Die Entstehung der $\alpha$-Pyrrolidincarbonsäure aus dem einfachsten bisher bekannten Gliede der Eiweißgruppe scheint mir ein bedeutendes Interesse $\mathrm{zu}$ beanspruchen. Ich habe trotzdem mit der Publikation gezögert, weil sich an diesen Befund weitere Fragen knüpften, die ich nach Darstellung neuen Materials zu entscheiden und in weiterem Zusammenhang mitzuteilen hoffte. Leider ist es mir in den beiden folgenden Wintern 1901 und 1902 nicht möglich gewesen, Lachstestikel zu erhalten, und ich sehe mich daher in der Lage, meine vor drei Jahren gewonnenen Ergebnisse ohne die weiteren Ausführungen mitzuteilen.

Ich bin in Gemeinschaft mit Herrn Dr. Dakin mit der weiteren Untersuchung der Spaltungsprodukte der Protamine beschäftigt.

\title{
Entgegnung an Dr. J. Weiß. ${ }^{1}$ ) \\ Von
}

Dr. Frz. Hupfer.

(Der Redaktion zugegangen am 7. November 1903.)

Herr Dr. Weiß versucht, die Verschiedenheit meiner, ${ }^{2}$ ) bei Einwirkung von Chinasäure auf den Organismus gefundenen Resultate gegen seine $^{3}$ ) als auf individueller Eigenschaft meines Organismus beruhend, zu erklären. Ich habe nun diese Versuche an drei weiteren Personen, in verschiedenen Lebensaltern, mit Innehaltung genauester Stoffwechselkontrolle wiederholt und bin zu dem Ergebnis gelangt, daß in keinem Falle nach $20 \mathrm{~g}$ täglicher Chinasäureeingabe auch nur der geringste Einfluß auf Harnsäure konstatiert werden konnte. Da sich auch die Befunde von Förster ${ }^{4}$ ) und von Ulrici ${ }^{5}$ ) vollständig mit meinen Resultaten decken, so muß es wohl im Gegenteil als Anomalie des Weißschen Organismus aufgefaßt werden, wenn dieser nach eingeführter Chinasäure mit verminderter Harnsäureausfuhr reagiert.

1) Weiß, Diese Zeitschr., Bd. XXXVIII, Heft 2, 1903.

2) Hupfer, Diese Zeitschr., Bd. XXXVII, Heft 4, S. 302, 1903.

s) Weiß, Diese Zeitschr., Bd. XXV, S. 393, 1898. Ebenda, Bd. XXVII, S. 216, 1899.

4) Förster, Dissertat. Breslau 1900.

5) Ulrici, Arch. f. exp. Pathol. u. Pharm., Bd. 46, S. 321, 1901. 